\title{
BERRIES SUPPLEMENTATION MODULATES BODY WEIGHT AND METABOLIC DETERIORATIONS IN OBESE RATS
}

\author{
FAROUK K EL-BAZ ${ }^{1 *}$, HANAN F. ALY ${ }^{2}$, HOWAIDA I. ABD-ALLA ${ }^{3}$ \\ ${ }^{1}$ Department of Plant Biochemistry, National Research Centre, 33 El Bohouthst (Former El Tahrirst), Dokki, Giza, P.0. 12622, Egypt. \\ ${ }^{2}$ Department of Therapeutic Chemistry, National Research Centre, 33 El Bohouthst (Former El Tahrirst), Dokki, Giza, P.O. 12622, Egypt. \\ ${ }^{3}$ Department of Chemistry of Natural Compounds, National Research Centre, 33 El Bohouth St. (Former El Tahrirst), Dokki, Giza, P.O. \\ 12622, Egypt. Email: fa_elbaz@hotmail.com
}

Received: 07 November 2017, Revised and Accepted: 11 December 2017

\section{ABSTRACT}

Objective: The aim of the present work is to investigate the potential of purple (Morus rubra [MR]) and white (Morus alba [MA]) berry supplementation to modulate body weight (BW) and metabolic deteriorations in obese Wistar male rats.

Methods: Seventy rats weighing $150.00 \pm 10 \mathrm{~g}$ (mean \pm standard deviation) were used; the rats were randomly divided into seven groups of $10 \mathrm{rats}$ each. Obesity was induced by feeding animals high-fat diet (HFD), for 6 consecutive weeks then treated with the purple (MR) and white (MA) berry ethanol extracts for 6 weeks in a dose $300 \mathrm{mg} / \mathrm{Kg} \mathrm{BW}$. BW gain, food intake fecal fat content, food consumptions were determined. The fats and organs such as liver, kidney, and heart were also weighed. Lipid profiles included triglyceride, total cholesterol, low-density lipoprotein cholesterol, and high-density lipoprotein cholesterol, as well as liverenzymes; alanine aminotransferase, alkaline phosphatase, aspartate aminotransferase, $\gamma$-glutamyltransferase $(\gamma$-GGT), and leptin were also determined.

Results: Treatment of obese rats with white and purple berries showed significant reduction in BW reached to 23.68\% with MR and $21.19 \%$ with MA berries compared to Orlistat (31.16\%). Liver weight, visceral fat, and liver enzyme activities were also markedly ameliorated. In addition, lipid profile biomarkers were improved on treated obese rats with both Morus species. In addition, increase in fecal fat (250.73\% and 256.25\%, for MR and MA, respectively) was noticed while blood glucose, insulin, leptin levels, and pancreatic lipase activity was improved. In addition, supplementing obese rats with both Morus species extract significantly increase food intake reached $33.33 \%$ and $36.66 \%$, for MR and MA, respectively.

Conclusion: The ameliorating effect of both Morus extracts may be attributed to polyphenolic rich compounds which have antioxidant properties, suppressed lipid synthesis in hepatic tissue and inhibited pancreatic lipase activity which consequently recommended using as a promising antiobesity agents.

Keywords: Obesity, Berry, Lipid profile, Pancreatic lipase, Leptin level, Visceral fat.

(c) 2018 The Authors. Published by Innovare Academic Sciences Pvt Ltd. This is an open access article under the CC BY license (http://creativecommons. org/licenses/by/4. 0/) DOI: http://dx.doi.org/10.22159/ajpcr.2018.v11i3.23522

\section{INTRODUCTION}

Obesity is a serious health problem around the world and is associated with an increased risk of complications including insulin resistance, dyslipidemia, and diabetes mellitus [1]. Obesity is also coincided with metabolic alterations including nonalcoholic fatty liver disease (NAFLD) and characterized by hyperleptinemia [2].

The occurrence of NAFLD is rising in parallel with insulin resistance and the epidemic of obesity and that is joined to the diet of most global populations [3]. The liver is considered for the regulation of entire body energy homeostasis because of its central role in glucose and lipid metabolism.

High-fat diets (HFDs) have been shown to induce dysregulated gene expression of hepatic tissues which affect cholesterol, lipid, oxidative, and inflammatory pathways [4]. NAFLD is characterized by the increase of lipids and its derivatives in liver tissues and increase the potential damage by induction of fibrosis and inflammation, due to oxidative stress induction [5].

Healthy body weight (BW) is affected by the types of foods. It is recommended that increase in the consumption of fruit and vegetables, protecting the body from incidence of high weight gain and therefore, preventing NAFLD of obesity [6].
Morus, also called berry, is a well-known functional food and medicinal herb. The herb has been used as a remedy for dysentery, diuretic, expectorant, and antidiabetic in traditional medicine. The fruits of berries have been made into a variety of food products [7].

Leaves of berry have been known to possess beneficial insulin tropic properties and its antioxidant potential can yield protection against complications of diabetes mellitus [8]. A positive effect was exhibited by Morus tea supplement as it reduces the post-prandial hyperglycemia type-2 diabetes [9].

Berries are rich in polyphenolic compounds which may cause a reduction of accumulated fat in liver tissues [10]. Polyphenolic compounds are commonly metabolized in the liver and intestine, in which they recalculate in the hepatic circulation and several metabolites association with hepatic and immune cells [11].

Morus species are multifunctional plants with promising medicinal properties [12]. Many reports indicated that berries are a good source of micronutrients, stilbenes, anthocyanins, flavonoids, and benzofurans $[12,13]$. These compounds have shown a wide range of bioactive features including hypoglycemic, neuroprotective functions, anti-inflammatory, and antioxidative effects $[10,14,15]$. Therefore, the objective of the present study is to investigate the potency of purple and white berry extracts on obesity induced by HFD through measuring 
different physiological biomarkers related metabolic changes including liver function enzyme activities, BW gain percentage, organ weight, food intake, visceral and fecal fats percentages, blood glucose, insulin, and leptin levels as well as pancreatic lipase activity.

\section{MATERIALS AND METHODS}

\section{Collection of plant material}

Fresh fruits of white Morus alba (MA) and purple Morus rubra (MR) were collected in the Delta region, Egypt. The berries were selected according to uniformity of shape and color. The identification of the plant was confirmed by Therese Labib, Herbarium Section, El-Orman Botanical Garden, Giza, and Egypt. The fresh fruit samples were cleaned, stored in polyethylene bags and frozen at $-20^{\circ} \mathrm{C}$, till further use.

\section{Preparation of extracts for bioassays}

The fresh fruits of each species $(200 \mathrm{~g})$ were extracted separately with $700 \mathrm{~mL}$ of $70 \%$ aqueous ethanol (EtOH) for $3 \mathrm{~h}$, on an orbital shaker in the dark at room temperature. Each extract was separated by centrifugation $(13,000 \times g, 10 \mathrm{~min})$, the supernatant was taken, the residue was resuspended in $50 \mathrm{~mL}$ of the same solvent, and the mixture was again separated by centrifugation. The two resulting supernatants were then combined and concentrated under reduced pressure at $40^{\circ} \mathrm{C}$ till dryness to get $2.54 \%$ and $2.39 \%$ of crude EtOH extract of MA and $\mathrm{MR}$, respectively. The residues were stored in the dark at $-20^{\circ} \mathrm{C}$.

\section{Biological assay}

\section{Experimental animals}

Male albino rats $(n=50)$ weighted $(150 \pm 10 \mathrm{~g})$, were obtained from the Animal House of the National Research Centre (NRC). Animals were quarantined and allowed to acclimate for 10 days before beginning experimentation. They were housed 10 per cage under temperature controlled environment $\left(26-29^{\circ} \mathrm{C}\right)$ with a fixed light/dark cycle with free access to water and food. All procedures of the present study were performed according to the Ethical Committee of the NRC, Egypt, provided that the animals will not suffer at any stage of the experiment.

\section{Induction of obesity in rats}

Obesity was induced in rats according to the method of Adaramoye et al. [16] by feeding rat's HFD of cholesterol. Cholesterol was orally administrated at a dose of ( $30 \mathrm{mg} / 0.3 \mathrm{~mL}$ olive oil $/ \mathrm{kg}$ animal) 5 times a week for 12 consecutive weeks. Lard fat was mixed with normal diet (ND) (1 kg of animal lard was added to $5 \mathrm{~kg}$ of ND). The occurrence of obesity was determined by measuring BW gain percentages, visceral and fecal fat percentages.

\section{Doses and routs of administration}

Obese rats received an oral dose of $2 \mathrm{mg} / \mathrm{kg}$ BW dissolved in distilled water of the antiobesity reference drug; Orlistat $(12 \mathrm{mg} / \mathrm{kg})$ for 6 weeks [17]. Purple and white berry ethanol extracts were administered orally for 6 weeks in a dose $300 \mathrm{mg} / \mathrm{kg}$ BW [18].

\section{Determination of BW gain, food intake, and energy intake}

BW change and food intake was measured according to the method of Akase et al. [19]. Intake of food was measured weekly on a cage basis and expressed as gof food/day. Initial BW of all animals was measured before they were fed with either ND or HFD for 12 weeks. At the end of each week, the weight gain percentage was calculated as followed:

$$
\text { Weight gain } \%=\frac{\text { New weight } \mathrm{W}_{1} \text { - Initial weight } \mathrm{W}_{0}}{\text { Initial weight } \mathrm{W}_{0}} \times 100
$$

\section{Determination of fecal fat content}

Fecal fat content of the rats was determined based on the slightly modified method described by Bligh and Dyer [20]. Briefly, feces $(0.5 \mathrm{~g})$ were soaked in $2 \mathrm{~mL}$ distilled water and homogenized completely. It was then stored at $4^{\circ} \mathrm{C}$ for $24 \mathrm{~h}$ followed by homogenization by vortex for 1 min. Extraction of lipids from feces was executed using $7.5 \mathrm{~mL}$ chloroform: methanol $(1: 2, \mathrm{v}: \mathrm{V})$ for $30 \mathrm{~min}$, followed by the addition of $2.5 \mathrm{~mL}$ of chloroform, and deionized water and shaking for another $30 \mathrm{~min}$. Resultant mixtures were then centrifuged (at 2000×g, $15 \mathrm{~min}$ ). The lipophilic layer was isolated and dried under reduced pressure.

\section{Food consumption}

Individual BW gains were recorded before study imitation (Day 0), and weekly thereafter. Mean BW gains were calculated for each group at each interval and for the overall testing interval. During the study, food consumptions were measured weekly per cage and mean food consumptions by individual rats were calculated [15].

\section{Experimental design}

Seventy male Wistar albino rats weighing at $150.00 \pm 10 \mathrm{~g}$ (mean \pm standard deviation [SD]) were used. Weight of rats was on the day received from supplier. After adaptation period to the environment, the rats were randomly divided into seven groups ( $\mathrm{n}=10 /$ group) as follows: Group (1) is the ND feeding rats (ND). Group (2) and (3) are ND rats treated with $300 \mathrm{mg} / \mathrm{kg} \mathrm{BW}$ of MR and MA extracts for 12 consecutive weeks (control ND/MR and control ND/MA, respectively). Group (4) is the HFD-treated rats for 12 weeks. Groups (5) and (6) are obese rats treated for 6 weeks with $300 \mathrm{mg} / \mathrm{kg} \mathrm{BW}$ of ethanolic extract of purple and white berry (HFD/MR and HFD/MA, respectively). Group (7) is the obese rats treated for 6 weeks with anti-obesity standard drug Oristatst (OS) $(12 \mathrm{mg} / \mathrm{kg}$ BW) (HFD/OS). Health conditions of all rats were monitored daily and no adverse events were observed throughout the study. At the beginning of the experiments, the weights of all rats were recorded at $155.00 \pm 5.00 \mathrm{~g}$ (weight of rats after 10 days of acclimatization). All experiments and biochemical analysis were conducted using 50 rats with triplicate measurements. The permission to conduct this study was according to the ethics of NRC, Egypt.

Blood sample and collection of serum liver, kidney, heart, visceral fats, and feces

Blood samples were obtained fallowing an overnight fasting state at the end of treatment (week 12) at 8 a.m. Samples were withdrawn from a cubital vein into blood tubes under diethyl ether anesthesia and immediately stored on ice a $t 4^{\circ} \mathrm{C}$. The serum was then separated from the cells by centrifugation at $3000 \mathrm{rpm}$ for $10 \mathrm{~min}$ and they were stored until analyzing at $-80^{\circ} \mathrm{C}$ [21]. After 12 and 18 weeks of treatment, all the rats were sacrificed. The fats and organs such liver, kidney, and heart were also weighed. Feces were collected in the final week of the study for the determination of fecal fat content.

\section{Biochemical measurements}

Various biochemical parameters were measured including lipid profiles of plasma triglyceride (TG), total cholesterol (TC), lowdensity lipoprotein cholesterol (LDL-C) and high-density lipoprotein cholesterol (HDL-C) (Biodiagnostic, Egypt), liver enzymes of alanine aminotransferase (ALT), alkaline phosphatase (ALP), aspartate aminotransferase (AST), $\gamma$-glutamyltransferase $(\gamma$-GGT) (Biodiagnostic, Egypt), insulin (Mercodia Rat Insulin ELISA Kit, Uppsala, Sweden), leptin (RayBio Rat Leptin ELISA kit, Norcross, GA, USA, Cat\# ELRLeptin-001). Concentration of LDL-C was calculated by Friedwald's formula [22]. Whereas the serum, TG, and HDL-C were determined using enzymatic colorimetric methods according to Kostner [23]. ALT and AST activities enzymes were estimated according to Reitman and Frankel [24]. ALP was measured by the method of Belfield and Goldberg [25] using a diagnostic kit (Biosystems, Egypt). Serum $\gamma$-GGT activity was measured according to Persijnandvan der Slik [26] using QCA Diagnostic kits (Spain). Pancreatic lipase activity was performed according to previously described method [27].

\section{Statistical analysis}

Data are expressed as mean \pm SD of 10 rats in each group. Statistical analysis is carried out using SPSS compute program coupled with 
CO-state computer program, where unshared letters are significant at $\mathrm{p} \leq 0.05$.

\section{RESULTS}

The effects of purple and white berries were evaluated on the following.

\section{BW gain percentage and food intake in obese rats}

Significant increase was noticed in BW gain reached to $140.63 \%$ in obese rats feed HFD for 12 weeks. While, significant reduction in BW gain in HFD treated rats with MR berry $(-23.68 \%)$, MA berry $(-21.19 \%)$ compared to Orlistat (31.16\%). Beside, food intake showed insignificant change in control rats treated either with red or white berry extracts compared to normal control untreated rats. In addition, HFD feed rats showed insignificant change in food intake compared to control one. However, obese treated rats with purple, white, and standard drug exhibited significant increase in food intake with percentage increase reached to $33.33,36.66$, and $25.55 \%$, respectively (Table 1 ).

\section{Visceral and fecal fats percentage in obese rats}

Table 2 clearly demonstrated significant increase in visceral fat in obese rats (HFD) with percentage $285.80 \%$. While significant reduction in visceral fat in obese rats treated with MR $(-39.79 \%)$, and MA extract $(-38.29 \%)$, was noticed compared with standard drug (-55.01\%). Further, significant increase in fecal fat was recorded in obese rats with percentage $110.29 \%$, compared to control rats. Obvious increase reached to $250.73,256.25$, and $396.32 \%$ on treated obese rats with MR, MA, and OS, respectively.

\section{Organ weights of obese rats treated for 6 weeks}

Table 3, indicated significant increase in liver weight in obese rats with percentage increase $45.16 \%$. Treatment of obese rats with purple and white berry extracts as well as OS as reference drug showed significant reduction in liver weight by 18.88 and 14.44 and $22.22 \%$, respectively compared to HFD-rats liver. While insignificant change was detected in cardiac and renal tissues in obese rats compared to normal control one.

Insulin, blood glucose, leptin levels, and pancreatic lipase activity in treated obese rats

Results indicated in Table 4, showed significant increase in blood glucose, insulin, leptin levels and pancreatic lipase activity in obese rats (G4) with percentage $79.08,52.00,70.54$ and $240.29 \%$, respectively compared to control one. Noticeable improvement in blood glucose levels was noticed recorded 35.69, 25.60 and 45.67\%, respectively, on treated obese rats with red, white and OS reference drug. Also, treatment of obese rats with red and white berry extracts demonstrated improvement in insulin level by 9.52 and $12.00 \%$, respectively while normalization in its level was noticed with OS (38.07\%). Further, lipase activity in obese rats treated with red and white berry extracts recorded improvement percentages reached to 32.55 and $50.38 \%$, respectively, while normalization in its activity was noticed using OS. In addition, obvious improvement was recorded also for leptin level in obese rats treated with both purple and white extracts as well as standard drug (94.66, 67.96 and $218.93 \%$, respectively)

Liver function enzymes in obese rats for 6 weeks of treatment post induction with HFD

Table 5 demonstrated insignificant change in all liver function enzyme activities in ND feed rats and treated with red and white berries as compared to control one. While obese induced rats with HFD exhibited significant increase in all liver function enzymes reached to 79.83 , 41.04, 199.82 and 75.57\%, for ALT, AST, $\gamma$-GGT, and ALP, respectively.

Table 1: Effects of Morus rubra and Morus alba extract on body weight gain percentage and food intake in obese rats

\begin{tabular}{|c|c|c|c|c|c|c|c|}
\hline BW gain & Control ND & Control ND/MR & ND/MA control & HFD & HFD/MR & HFD/MA & HFD/OS \\
\hline Initial body weight (g) & $155.00^{\mathrm{a}} \pm 4.16$ & $150.00^{\mathrm{a}} \pm 4.26$ & $158.00^{\mathrm{a}} \pm 4.90$ & $160.00^{\mathrm{a}} \pm 2.32$ & $380.00^{\mathrm{b}} \pm 4.77$ & $387.00^{\mathrm{b}} \pm 2.12$ & $385.00^{\mathrm{b}} \pm 8.88$ \\
\hline Final body Weight (g) & $195.00^{c} \pm 4.99$ & $180.00^{c} \pm 6.34$ & $189.00^{c} \pm 3.26$ & $385.00^{\mathrm{b}} \pm 3.26$ & $290.00^{\mathrm{d}} \pm 7.55$ & $305.00^{\mathrm{d}} \pm 8.00$ & $265.00^{\mathrm{e}} \pm 7.20$ \\
\hline Body weight gain (\%) & $25.80^{\mathrm{a}} \pm 2.88$ & $20.00^{\mathrm{b}} \pm 1.00$ & $19.62^{\mathrm{b}} \pm 0.76$ & $140.63^{c} \pm 6.87$ & $-23.68^{\mathrm{d}} \pm 1.99$ & $-21.19^{\mathrm{d}} \pm 0.44$ & $-31.16^{\mathrm{e}} \pm 0.66$ \\
\hline \%improvement & & & & & 453.29 & 462.94 & 424.3 \\
\hline Food intake (g/week) & $180.00^{\mathrm{a}} \pm 6.77$ & $179.00^{\mathrm{a}} \pm 4.16$ & $185.00^{\mathrm{a}} \pm 3.65$ & $176.00^{\mathrm{a}} \pm 8.54$ & $240.00^{\mathrm{b}} \pm 6.64$ & $246.00^{\mathrm{b}} \pm 5.88$ & $226.00^{\mathrm{b}} \pm 2.00$ \\
\hline$\%$ change & - & 0.5 & 2.77 & 2.22 & 33.33 & 36.66 & 25.55 \\
\hline
\end{tabular}

ND: Normal diet, ND/MR: Rats feed normal diet and treated orally with MR extract for 6 weeks. ND/MA: Rats feed normal diet and treated orally with Morus alba extract for 6 weeks. HFD: Rats feed with HFD for 12 weeks. HFD/MR: HFD fed rats treated orally with MR for 6 weeks post-induction. HFD/MA: HFD fed rats treated orally with Morus alba for 6 weeks post induction. FHD/OS: Rats feed HFD and treated orally for 4 weeks with Orlistat standard drug. Statistical analysis is carried out using SPSS computer program combined with co-state computer program. Unshared letter is significant at $\mathrm{P} \leq 0.05$. HFD: High-fat diet

Table 2: Effects of Morus rubra and Morus alba extract on of visceral and fecal fats percentage in obese rats

\begin{tabular}{|c|c|c|c|c|c|c|c|}
\hline Parameters & Control ND & Control ND/MR & ND/MA control & HFD & HFD/MR & HFD/MA & HFD/OS \\
\hline Visceral fat (\%) & $1.55^{\mathrm{a}} \pm 0.55$ & $1.52^{\mathrm{a}} \pm 0.05$ & $1.50^{\mathrm{a}} \pm 0.06$ & $5.98^{\mathrm{b}} \pm 0.71$ & $3.60^{c} \pm 0.09$ & $3.69^{c} \pm 0.56$ & $2.69^{d} \pm 0.30$ \\
\hline$\%$ change & & -1.93 & -1.50 & 285.8 & -39.79 & -38.29 & -55.01 \\
\hline Fecal fat (\%) & $2.72^{\mathrm{a}} \pm 0.25$ & $2.89^{\mathrm{a}} \pm 0.21$ & $2.80^{\mathrm{a}} \pm 0.22$ & $5.72^{\mathrm{b}} \pm 0.91$ & $9.54^{c} \pm 0.68$ & $9.69^{c} \pm 0.66$ & $13.50^{\mathrm{e}} \pm 0.96$ \\
\hline$\%$ change & & 6.25 & 8 & 110.29 & 250.73 & 256.25 & 396.32 \\
\hline
\end{tabular}

ND: Normal diet, ND/MR: Rats feed normal diet and treated orally with Morus rubra extract for 6 weeks. ND/MA: Rats feed normal diet and treated orally with Morus alba extract for 6 weeks. HFD: Rats feed with HFD for 12 weeks. HFD/MR: HFD fed rats treated orally with Morus rubra for 6 weeks post induction. HFD/MA: HFD-fed rats treated orally with MA for 6 weeks post induction. FHD/OS: Rats feed HFD and treated orally for 4 weeks with Orlistat standard drug. Statistical analysis is carried out using SPSS computer program combined with co-state computer program. Unshared letter is significant at P $\leq 0.05$. HFD: High-fat diet

Table 3: Organ weights of obese rats treated with Morus rubra and Morus alba for 6 weeks

\begin{tabular}{|c|c|c|c|c|c|c|c|}
\hline Organ weights & Control ND & Control ND/MR & ND/MA control & HFD & HFD/MR & HFD/MA & HFD/OS \\
\hline Liver weight (g) & $6.20^{\mathrm{a}} \pm 0.16$ & $6.00^{\mathrm{a}} \pm 0.26$ & $5.80^{\mathrm{a}} \pm 0.70$ & $9.00^{\mathrm{b}} \pm 0.36$ & $7.30^{c} \pm 0.77$ & $7.70^{c} \pm 2.12$ & $7.00^{\mathrm{a}} \pm 8.88$ \\
\hline$\%$ change & & -3.22 & -6.45 & 45.16 & 18.88 & 14.44 & 22.22 \\
\hline Heart weight (g) & $1.05^{c} \pm 0.09$ & $1.25^{c} \pm 0.34$ & $1.19 c \pm 0.20$ & $1.22^{c} \pm 0.16$ & $1.20^{c} \pm 0.25$ & $1.05^{c} \pm 0.04$ & $1.26^{c} \pm 0.20$ \\
\hline Kidney eight (g) & $2.80^{\mathrm{a}} \pm 0.37$ & $2.73^{\mathrm{a}} \pm 0.26$ & $2.85^{\mathrm{a}} \pm 0.69$ & $2.76^{a} \pm 0.59$ & $2.85^{\mathrm{a}} \pm 0.34$ & $2.56^{\mathrm{a}} \pm 0.38$ & $2.67^{\mathrm{a}} \pm 0.10$ \\
\hline
\end{tabular}

ND: Normal diet, ND/MR: Rats feed normal diet and treated orally with Morus rubra extract for 6 weeks. ND/MA: Rats feed normal diet and treated orally with Morus alba extract for 6 weeks. HFD: Rats feed with HFD for 12 weeks. HFD/MR: HFD fed rats treated orally with MR for 6 weeks post-induction. HFD/MA: HFD-fed rats treated orally with Morus alba for 6 weeks post-induction. FHD/OS: Rats feed HFD and treated orally for 4 weeks with Orlistat standard drug. Statistical analysis is carried out using SPSS computer program combined with co-state computer program. Unshared letter is significant at P $\leq 0.05$. HFD: High-fat diet 
On the other hand, obese rats treated with MR and MA extracts showed more or less similar results with higher percentages of improvement for MR than MA (as indicated in the Table 1), compared with standard anti-obese drug.

\section{Lipid profile in obese rats for 6 weeks of treatment post induction} with HFD

Table 6 declared insignificant change in lipid profile in ND-feed rats and treated with MR and MA extract compared with normal control untreated rats. While, HFD rats recorded significant increase in all lipid profile biomarkers with percentages 90.65, 99.73, and 53.64\%, respectively, for TC, TG, LDL-C. While, HDL-C showed significant reduction (43.87\%), compared to control rats. Meanwhile, obese rats treated with purple MR and white MA berry extracts showed marked normalization in TC, HDL-C, TG, LDL-C compared to obese untreated rats with higher percentages of improvement for MR $(43.44,38.16$, 64.78 , and $27.27 \%$, respectively), compared to OS anti-obesity standard drug which recorded $76.00,30.14,95.92$, and $36.36 \%$, respectively.

\section{DISCUSSION}

The present results declared that, significant increase in BW gain percentage $(140.63 \%)$ in HFD fed rats, while significant reduction in the percentages of BW gain in obese rats treated with purple $(-23.68 \%)$ and white berry $(-21.19 \%)$ extracts compared to OS $(-31.16 \%)$. However, food intake in HFD fed rats didn't differed significantly as compared to control. On the other hand, food intake showed significant increase in obese rats treated with purple, white and standard drug compared to HFD fed rats with percentages increase reached to 33.33, 36.66 , and $25.55 \%$, respectively. In connection with the present results, Salih et al. [9] suggested that the increase feed intake may enhance energy balance or caloric storage, hence increase BW in rats. However, it has been reported that BW gain may occur independent of increased feed intake [28]

The improved effect of berry may be related to the activation of glycolysis in the liver and up-regulation of genes related to cholesterol metabolism [13]. Morus species possess many bioactive compounds, such as deoxymycine, flavonol glycosides, and anthocyanins that may suppress the elevation of postprandial blood glucose and secretion of insulin $[13,29]$. These compounds may also regulate hepatic gluconeogenesis illustrating an antihyperglycemic effect of Morus species.

With flavonoids as major constituents, the plant leaves possess various biological activities, including antioxidant, antimicrobial, skin-whitening, cytotoxic, antidiabetic, glucosidase inhibition, antihyperlipidemic, anti-atherosclerotic, anti-obesity, cardioprotective, and

Table 4: Effect of insulin, blood glucose, leptin levels, and pancreatic lipase activity in obese rats treated with Morus rubra and Morus alba extracts

\begin{tabular}{|c|c|c|c|c|c|c|c|}
\hline Bioch. Parameters & Control ND & Control ND/MR & ND/MA control & HFD & HFD/MR & HFD/MA & HFD/OS \\
\hline Glucose (mg/dl) & $83.20^{\mathrm{a}} \pm 6.16$ & $86.00^{\mathrm{a}} \pm 7.26$ & $85.70^{\mathrm{a}} \pm 6.70$ & $149.00^{\mathrm{b}} \pm 3.36$ & $119.30^{c} \pm 2.77$ & $127.70^{c} \pm 2.12$ & $111.00^{c} \pm 8.88$ \\
\hline$\%$ change & - & 3.36 & 3 & 79.08 & 43.38 & 53.48 & 33.41 \\
\hline \%improvement & & & & & 35.69 & 25.6 & 45.67 \\
\hline Insulin (Ul/U/mL) & $7.25^{c} \pm 0.19$ & $7.00^{c} \pm 0.44$ & $7.19^{c} \pm 0.10$ & $11.02^{\mathrm{d}} \pm 0.16$ & $10.33^{\mathrm{d}} \pm 0.25$ & $10.15^{\mathrm{d}} \pm 0.34$ & $8.26^{c} \pm 0.60$ \\
\hline$\%$ change & - & 3.44 & 0.83 & 52 & 42.48 & 40 & 13.93 \\
\hline \%improvement & & & & & 9.52 & 12 & 38.07 \\
\hline Lipase ) UL) & $12.90^{\mathrm{a}} \pm 2.22$ & $12.70^{\mathrm{a}} \pm 1.26$ & $12.85^{\mathrm{a}} \pm 1.69$ & $22.00^{\mathrm{b}} \pm 1.59$ & $17.80^{\mathrm{c}} \pm 1.34$ & $15.50^{\mathrm{c}} \pm 0.38$ & $12.67^{\mathrm{d}} \pm 0.10$ \\
\hline \%improvement & & & & & 32.55 & 50.38 & 72.32 \\
\hline Leptin (ng/mL) & $4.12^{\mathrm{a}} \pm 0.02$ & $4.33^{\mathrm{a}} \pm 0.06$ & $4.00^{\mathrm{a}} \pm 0.04$ & $14.02^{\mathrm{b}} \pm 0.06$ & $10.12^{\mathrm{c}} \pm 0.50$ & $11.22^{\mathrm{c}} \pm 0.15$ & $5.00^{\mathrm{d}} \pm 0.45$ \\
\hline$\%$ change & & 5.09 & 2.9 & 240.29 & 145.63 & 172.33 & 21.36 \\
\hline \%improvement & & & & & 94.66 & 67.96 & 218.93 \\
\hline
\end{tabular}

ND: Normal diet, ND/MR: Rats feed normal diet and treated orally with Morus rubra extract for 6 weeks. ND/MA: Rats feed normal diet and treated orally with Morus alba extract for 6 weeks. HFD: Rats feed with HFD for 12 weeks. HFD/MR: HFD fed rats treated orally with Morus rubra for 6 weeks post-induction. HFD/MA: HFD fed rats treated orally with Morus alba for 6 weeks post-induction. FHD/OS: Rats feed HFD and treated orally for 4 weeks with Orlistat standard drug. Statistical analysis is carried out using SPSS computer program combined with costate computer program. Unshared letter is significant at P $\leq 0.05$. HFD: High-fat diet

Table 5: Effect of purple and white berries on liver function enzymes in obese rats for 6 weeks of treatment post induction with HFD

\begin{tabular}{|c|c|c|c|c|c|c|c|}
\hline Bioch. Parameters & Control ND & Control ND/MR & Control ND/MA & HFD & HFD/MR & HFD/MA & HFD/OS \\
\hline ALT (U/l) & $49.00^{\mathrm{a}} \pm 0.22$ & $43.00^{\mathrm{a}} \pm 3.11$ & $46.00^{\mathrm{a}} \pm 2.80$ & $88.12^{\mathrm{b}} \pm 3.23$ & $60.10^{c} \pm 3.23$ & $63.10^{c} \pm 4.00$ & $53.80^{\mathrm{d}} \pm 4.78$ \\
\hline$\%$ change & - & -12.24 & -6.12 & 79.83 & 22.65 & 28.77 & 9.79 \\
\hline$\%$ improvement & & & & & 57.18 & 51.06 & 70.04 \\
\hline AST (U/l) & $44.10^{\mathrm{a}} \pm 3.21$ & $40.00^{\mathrm{a}} \pm 1.67$ & $42.00^{\mathrm{a}} \pm 1.54$ & $62.20^{\mathrm{b}} \pm 2.14$ & $53.89^{c} \pm 2.75$ & $52.44^{\mathrm{c}} \pm 5.10$ & $52.42^{c} \pm 1.90$ \\
\hline$\%$ change & - & -9.20 & -4.76 & 41.04 & 22.19 & 18.91 & 18.87 \\
\hline$\%$ improvement & & & & & 18.84 & 22.13 & 22.17 \\
\hline$\gamma$-GTT (U/l) & $22.00^{\mathrm{a}} \pm 0.77$ & $19.00^{\mathrm{a}} \pm 0.87$ & $19.54^{\mathrm{a}} \pm 0.32$ & $65.96^{\mathrm{b}} \pm 4.16$ & $35.00^{c} \pm 2$ & $37.90^{c} \pm 2.61$ & $25.06^{\mathrm{a}} \pm 0.67$ \\
\hline$\%$ change & & -13.63 & -11.18 & 199.82 & 59.09 & 72.27 & 13.91 \\
\hline$\%$ improvement & & & & & 140.73 & 127.54 & 185.90 \\
\hline ALP (U/l) & $80.90^{\mathrm{a}} \pm 5.33$ & $78.00^{\mathrm{a}} \pm 2.77$ & $80.00^{\mathrm{a}} \pm 3.00$ & $142.04^{\mathrm{b}} \pm 8.55$ & $100.00^{c} \pm 6.00$ & $103.00^{c} \pm 3.76$ & $88.00^{\mathrm{a}} \pm 3.15$ \\
\hline$\%$ change & & -3.58 & 1.11 & 75.57 & 23.60 & 27.31 & 8.77 \\
\hline$\%$ improvement & & & & & 51.95 & 48.25 & 66.79 \\
\hline
\end{tabular}

ND: Normal diet, ND/MR: Rats feed normal diet and treated orally with Morus rubra extract for 6 weeks. ND/MA: Rats feed normal diet and treated orally with MA extract for 6 weeks. HFD: Rats feed with HFD for 12 weeks. HFD/MR: HFD fed rats treated orally with Morus rubra for 6 weeks post-induction. HFD/MA: HFD fed rats treated orally with MA for 6 weeks post-induction. FHD/OS: Rats feed HFD and treated orally for 4 weeks with Orlistat standard drug. Statistical analysis is carried out using SPSS computer program combined with co-state computer program. Unshared letter is significant at P $\leq 0.05$. HFD: High-fat diet, ALT: Alanine aminotransferase, AST: Aspartate aminotransferase, $\gamma$-GTT: $\gamma$-glutamyltransferase, ALP: Alkaline phosphatase 
Table 6: Effect of Morus rubra and Morus alba on lipid profile in obese rats for 6 weeks of treatment post induction with HF

\begin{tabular}{|c|c|c|c|c|c|c|c|}
\hline Bioch. Parameters & Control ND & Control ND/MR & Control ND/MA & HFD & HFD/MR & HFD/MA & HFD/OS \\
\hline $\mathrm{TC}(\mathrm{mg} / \mathrm{dl})$ & $122.00^{\mathrm{a}} \pm 6.76$ & $120.00^{\mathrm{a}} \pm 3.65$ & $120.00^{\mathrm{a}} \pm 2.90$ & $232.6^{b} \pm 4.45$ & $179.6^{\mathrm{c}} \pm 8.15$ & $189.00^{c} \pm 6.4$ & $139.88^{\mathrm{e}} \pm 6.00$ \\
\hline$\%$ change & & 1.64 & 1.64 & 90.65 & 47.21 & 54.91 & 14.66 \\
\hline$\%$ improvement & & & & & 43.44 & 35.74 & 76.00 \\
\hline HDL-C (mg/dl) & $35.90^{\mathrm{a}} \pm 1.20$ & $37.00^{\mathrm{a}} \pm 3.00$ & $36.50^{\mathrm{a}} \pm 1.87$ & $20.15^{c} \pm 9.10$ & $33.85^{\mathrm{a}} \pm 0.10$ & $29.85^{c} \pm 8.10$ & $30.97^{\mathrm{d}} \pm 2.10$ \\
\hline$\%$ change & & 3.06 & 1.67 & 43.87 & 5.71 & 16.85 & 13.73 \\
\hline$\%$ improvement & & & & & 38.16 & 27.02 & 30.14 \\
\hline TG (mg/dl) & $96.33^{\mathrm{a}} \pm 2.44$ & $90.00^{\mathrm{a}} \pm 4.22$ & $93.00^{\mathrm{a}} \pm 1.22$ & $192.40^{\mathrm{b}} \pm 7.8$ & $130.00^{c} \pm 7.0$ & $132.90^{c} \pm 6.8$ & $100.00^{\mathrm{a}} \pm 3.00$ \\
\hline$\%$ improvement & & & & & 64.78 & 61.77 & 95.92 \\
\hline LDL-C (mg/dl) & $10.00^{\mathrm{a}} \pm 2.88$ & $96.00^{\mathrm{a}} \pm 3.22$ & $98.00^{\mathrm{a}} \pm 4.00$ & $169.00^{\mathrm{b}} \pm 2.00$ & $39.00^{c} \pm 4.99$ & $39.87^{c} \pm 6.00$ & $129.00^{\mathrm{d}} \pm 9.00$ \\
\hline$\%$ change & & 12.73 & 10.91 & 53.64 & 26.36 & 27.15 & 17.28 \\
\hline$\%$ improvement & & & & & 27.27 & 26.48 & 36.36 \\
\hline
\end{tabular}

ND: Normal diet, ND/MR: Rats feed normal diet and treated orally with Morus rubra extract for 6 weeks. ND/MA: Rats feed normal diet and treated orally with Morus alba extract for 6 weeks. HFD: Rats feed with HFD for 12 weeks. HFD/MR: HFD-fed rats treated orally with Morus rubra for 6 weeks post-induction. HFD/MA: HFD-fed rats treated orally with Morus alba for 6 weeks post-induction. FHD/OS: Rats feed HFD and treated orally for 4 weeks with Orlistat standard drug. Statistical analysis is carried out using SPSS computer program combined with co-state computer program. Unshared letter is significant at P $\leq 0.05$. HFD: High-fat diet, LDL-C: Low-density lipoprotein cholesterol, HDL-C: High-density lipoprotein cholesterol, TG: Triglyceride, TC: Total cholesterol

cognitive enhancement activities. Rich in anthocyanins and alkaloids, mulberry fruits have pharmacological properties, such as antioxidant, anti-diabetic, anti-atherosclerotic, anti-obesity, and hepatoprotective activities.

The plant extract may be effective for improving obesity-related metabolic stressors by the lower BW gain and epididymal adipocytesized espite the difference in food intake. The action of polyphenolic compounds could prevent ROS damage, and protect cells from free radicals [9]. Oxidative stress is considered as a critical mechanism of NAFLD. Moreover, the present results demonstrated that increase in visceral fat (285.80\%) of HFD rats, while fecal fats increased by $110.29 \%$, compared to control rats. However, obese rats treated with purple and white berry extracts revealed significant reduction in visceral fats reached to 39.79 and $38.29 \%$, respectively compared to OS (55.01\%). While, fecal fat demonstrated significant increase by percentages $250.73,256.25$, and $396.32 \%$ on treated obese rats with purple, white, and OS reference drug. In addition, the present data indicated significant increase in liver weight (45.16\%). However, liver weight exhibited significant decrease post-berry extracts therapy as well as OS comparing to HFD-fed rats with percentages $18.88,14.44$, and $22.22 \%$, respectively. However, kidney and heart tissue did not show a significant difference between groups. These comprehensive data could be explained based on increased liver TG depots which may cause further fat accumulation in hyperlipidemic mice leading to steatosis of macroand microvesicular. The rats treated by each Morus species may exhibit reduction in fat accumulation of liver as well as inhibition in adipocyte hypertrophy.

The current results revealed significant increase glucose, insulin, leptin levels, and lipase activity in HFD-fed rats compared to normal control one. While, amelioration in these biomarkers levels was noticed tendency berry extracts treatment. It was found that hypoxia of adipocyte, due to hypertrophy of adipose tissue, is a leading cause of obesity and can cause necrosis of adipocyte [30]. The later may cause macrophage infiltration and secretion of proinflammatory cytokine. It was suggested that tumor necrosis factor- $\alpha$ and interleukin (IL)- 6 inhibit the pathway of cascade signaling of insulin by preventing insulin receptors phosphorylation [31]. IL-1 $\beta$ also stimulates insulin resistance in adipocytes and its expression is upregulated in the adipose tissue of obese and insulin-resistant mice [32]

On the other hand, the increment in pancreatic lipase in HFD-fed rats may be due to its involvement in the TG absorption from the small intestine to the enterocytes and if somehow this initial movement of TG from the small intestinal lumen is blocked, hyperlipidemia can be prevented [27]. While, the improvement in its activity post berry therapy to HFD-fed rats may be related to berry can work as pancreatic lipase inhibitors whereby the digestion and absorption of fats can be suppressed while it increased the fecal lipid content in mice [30].

In addition, HFDs are considered to cause chronic inflammation in the hypothalamus and passivateleptin signaling, which are mechanisms mediating sustained appetite enhancement [33]. Fat accumulation and obesity are major underlying causes of chronic inflammation, due to the inherent ability of adipocytes to secrete adipokines which is an inflammatory mediator, and hormones like leptin [34]. The ameliorative effect of leptin level in obese rats treated with berry extracts may be related to polyphenolic compounds from berries which have been shown to decrease fat accumulation and suppress pancreatic lipase [35]. Therefore, berry extracts could be used against quite several diseases, since many of the biological actions of berry extracts have been attributed to their antioxidant properties.

The anti-obesity effect of purple berry may be involving the inhibition of pancreatic lipase activity and adipogenesis via the down-regulation of lipid accumulation. A quite vast range of polyphenolic compounds are found in berries and their intake on human health, performance, and disease are of valuable impact [36].

The results of the current work indicated significant increase in activities of liver function AST, ALT, ALP and $\gamma$-GGT in obese rats. While, treatment of obese rats with purple and white berries showed more or less similar results in modulating liver enzyme activities. In these concerns, Katsube et al. [29] speculated that oxidative stress is increased in obesity via nicotinamide adenine dinucleotide phosphate (NADPH) oxidase activation, and NADPH oxidase is a major source of reactive oxygen species (ROS) in various organs [37]. It has also been demonstrated that increased oxidative stress in the liver precedes high-fat diet, induced obesity, and insulin resistance [38]. Liver plays a central role in energy balance and keep insulin sensitivity, while the disturbance of its function by nutritional overload such as HFD feeding may result in steatosis, inflammation, and insulin resistance [38]. In the current study, the anti-obesity of MR could be related to the polyphenolic content such as flavonoids and anthocyanins that improve glucose metabolism through relaxation of oxidative stress in the liver derived from its antioxidant activities [39].

Long-term exposure to an HFD can cause NAFLD, a condition wherein large droplets of fat deposited in hepatocytes via the process of steatosis. Excessive cholesterol accumulation disrupts membrane fluidity, promotes cellular dysfunction, and thereby results in the progression fatty liver [40].

Our previous work reported the antiproliferative and radical scavenging effect of berries fruits [12]. In the present study, the supplementation of each Morus species to obese rats may increase expression of 
antioxidant enzymes to remove excess ROS production by the action of their bioactive secondary metabolites [41].

Fat accumulation in the liver increases LDL overproduction together with inflammatory cytokines lead to increase liver enzyme activities. On the other hand, the hepatoprotective activity of mulberry leaves on rat liver injury in diabetic rats or against varied hepatotoxic antirheumatic and analgesic drugs was reported Tag [42]. The possible ameliorative mechanism of the white and purple berries may be through free radical scavenger and antioxidant activity of its constituents, especially flavonoids which could prevent liver dysfunction.

The present study clearly indicated a significant increase in lipid profile TC, TG, and LDL-C, while, marked reduction in HDL-C in obese rats. The treatment of obese rats with purple and white berry extracts showed noticeable reduction in lipid profile, while elevation in HDL-C comparing with HFD-fed rats. The activity of the white berry (MA) may be attributed to quercetin 3-(6-malonylglucoside), the quantitatively major antioxidant flavonol glycoside [29].

Berry is a natural dietary supplement containing 1-deoxynojirimycin and other $\alpha$-glucosidase inhibitors in high concentration. These compounds hold some interesting mechanism of action regarding their hypoglycemic effect [13]. Moreover, the expression of LDL-R, a receptor mediating the endocytose of cholesterol-rich LDL, may be enhanced in the berry extracts, which was in line with the decreased plasma LDL-c levels [30]. HMG-CoA reductase, the rate-controlling enzyme in the pathway of cholesterol synthesis, also may be decreased in the berry extracts treated obese groups [30]. In a good agreement with the present results, Gaidhu et al. [43] found the expression levels of adipose TG lipase and hormone-sensitive lipase were both increased in the subcutaneous adipose tissue of HFD-induced obese mice. Flavanols and flavonols, condensed tannins (proanthocyanidins), hydrolysable tannins (ellagitannins and gallotannins), stilbenes, anthocyanins, and phenolic acids were reported as the most commonly found polyphenols in Morus fruits [13]. Polyphenols content may reduce plasma TG, TC, and LDL-C in hyperlipidemic rats $[15,44]$.

\section{CONCLUSION}

It could be concluded that the supplementation of obese rats with berry extracts which are rich with polyphenolic compounds, has antiaccumulation action of lipids and consequently anti-obesity properties. In addition, due to the antioxidant properties of berry extracts could be recommended for utilization as nutraceuticals against quite different human diseases. Consumption of berries may help to prevent obesity and obesity-related metabolic complications.

\section{AUTHOR CONTRIBUTION}

Farouk K El-Baz: Plan of work, writing revision, corresponding author. Hanan F. Aly: Experimental animals, Statistical analysis, writing. Howaida I. Abd-alla: Biochemical measurements, writing.

\section{CONFLICT OF INTERESTS}

Authors declare no conflict of interest.

\section{REFERENCES}

1. Mishra A, Gautam S, Pal S, Mishra A, Rawat KA, Maurya R, et al. Effect of Momordica charantia fruits on streptozotocin-induced diabetes mellitus and its associated complications. Int J Pharm Pharm Sci 2015;7:356-63.

2. Marjani A. A review on the role of triglyceride in metabolic syndrome. Asian J Pharm Clin Res 2015;8:1-3.

3. Tiniakos DG, Vos MB, Brunt EM. Nonalcoholic fatty liver disease: Pathology and pathogenesis. Annu Rev Pathol 2010;5:145-71.

4. Radonjic M, de Haan JR, van Erk MJ, van Dijk KW, van den Berg SA, de Groot PJ, et al. Genome-wide mRNA expression analysis of hepatic adaptation to high-fat diets reveals switch from an inflammatory to steatotic transcriptional program. PLoS One 2009;4:e6646.
5. Bechmann LP, Hannivoort RA, Gerken G, Hotamisligil GS, Trauner M, Canbay A, et al. The interaction of hepatic lipid and glucose metabolism in liver diseases. J Hepatol 2012;56:952-64.

6. Boeing H, Bechthold A, Bub A, Ellinger S, Haller D, Kroke A, et al. Critical review: Vegetables and fruit in the prevention of chronic diseases. Eur J Nutr 2012;51:637-63.

7. Wei H, Zhu J, Liu XQ, Feng WH, Wang ZM, Yan LH. Review of bioactive compounds from root barks of Morus plants (Sang-Bai-Pi) and their pharmacological effects. Cogent Chem 2016;2:1-16.

8. Gothai S, Ganesan P, Park SY, Fakurazi S, Choi DK, Arulselvan P, et al. Natural phyto-bioactive compounds for the treatment of Type 2 diabetes: Inflammation as a target. Nutrients 2016;8:1-28.

9. Salih ND, Hazir NS, Abo-Hamid MH. The effect of mulberry (Morus sp.) tea supplement on acetaminophen induced renal failure in rats. World J Pharm Pharm Sci 2015;4:111-25.

10. Pan S, Lakshmil A, Priyanka P. Anti-inflammatory activity of aqueous extract of Allium satium leaves. Asian J Pharm Clin Res 2015;8:81-7.

11. Joven J, Espinel E, Rull A, Aragonès G, Rodríguez-Gallego E, Camps J, et al. Plant-derived polyphenols regulate expression of miRNA paralogs miR-103/107 and miR-122 and prevent diet-induced fatty liver disease in hyperlipidemic mice. Biochim Biophys Acta 2012;1820:894-9.

12. El-Baz FK, Hassan AZ, Abd-Alla HI, Aly HF, Mahmoud K. Phytochemical analysis, assessment of ant proliferative and free radical scavenging activity of Morus alba and Morus rubra fruits. Asian J Pharm Clin Res 2017;10:189-99.

13. Chan EW, Lye PY, Wong SK. Phytochemistry, pharmacology, and clinical trials of Morus alba. Chin J Nat Med 2016;14:17-30.

14. Awad HM, Abd-Alla HI, Mahmoud KH, El-Toumy SA. In vitro antinitrosative, antioxidant, and cytotoxicity activities of plant flavonoids: A comparative study. Med Chem Res 2014;23:3298-307.

15. Shalaby NM, Abd-Alla HI, Aly HF, Albalawy MA, Shaker KH, Bouajila $\mathrm{J}$, et al. Preliminary in vitro and in vivo evaluation of antidiabetic activity of Ducrosia anethifolia boiss. And its linear furanocoumarins. Biomed Res Int 2014;2014:480545.

16. Adaramoye OA, Akintayo O, Achem J, Fafunso MA. Lipid-lowering effects of methanolic extracts of Vernonia amygdalina leaves in rats fed on high cholesterol diet. Vasc Health Risk Manag 2008;4:235-41.

17. Shalaby HM, Tawfek NS, Abo-El Hussein BK, Abd El-Ghany MS. The assessment of some biochemical and immunological effects by amphetamine and or listat on obesity in rats. Food Public Health 2014;4:185-92.

18. Hwang YJ, Lee EJ, Kim HR, Hwang KA. In vitro antioxidant and anticancer effects of solvent fractions from Prunella vulgaris var. Lilacina. BMC Complement Altern Med 2013;13:310.

19. Akase T, Shimada T, Terabayashi S, Ikeya Y, Sanada H, Aburada M. Antiobesity effects of Kaempferia parviflora in spontaneously obese Type II diabetic mice. J Nat Med 2011;65:73-80.

20. Bligh EG, Dyer WJ. A rapid method of total lipid extraction and purification. Can J Biochem Physiol 1959;37:911-7.

21. Selek S, Aslan M, Nazligul Y. Serum PON1 activity and oxidative stress in non-alcoholic fatty liver disease. J Harran Univ Med Fac 2012;9 Say1 3:85-91.

22. FruchartGG. LDL-cholesterol determination after separation of low density lipoprotein. Rev Fr Lab 1982;103:7-17.

23. Kostener CM. Letter: Enzymatic determination of cholesterol high density lipoprotein fraction prepared by polyanion precipitation. Clin Chem 1976;22:695.

24. Reitman S, Frankel S. A colorimetric method for the determination of serum glutamic oxalacetic and glutamic pyruvic transaminases. Am J Clin Pathol 1957;28:56-63.

25. Belfield A, Goldberg D. Colorimetric determination of alkaline phosphatase activity. Enzyme 1971;12:561-6.

26. Persijn JP, van der Slik W. A new method for the determination of gamma-glutamyl transferase in serum. J Clin Chem Clin Biochem 1976;14:421-7.

27. Tsuzuki W, Ue A, Nagao A, Endo M, Abe M. Inhibitory effect of lysophosphatidylcholine on pancreatic lipase-mediated hydrolysis in lipid emulsion. Biochim Biophys Acta 2004;1684:1-7.

28. Von Diemen V, Trindade EN, Trindade MR. Experimental model to induce obesity in rats. Acta Cir Bras 2006;21:425-9.

29. Katsube T, Yamasaki M, Shiwaku K, Ishijima T, Matsumoto I, Abec K, et al. Effect of flavonol glycoside in mulberry (Morus alba L.) leaf on glucose metabolism and oxidative stress in liver in diet-induced obese mice. J Sci Food Agric 2010;90:2386-92.

30. Li Z, Kim HJ, Park MS, Ji GE. Effects of fermented ginseng root and ginseng berry on obesity and lipid metabolism in mice fed a high-fat diet. J Ginseng Res 2017;2017:1-8. 
31. Karalis KP, Giannogonas P, Kodela E, Koutmani Y, Zoumakis M, Teli T, et al. Mechanisms of obesity and related pathology: Linking immune responses to metabolic stress. FEBS J 2009;276:5747-54.

32. Lagathu C, Yvan-Charvet L, Bastard JP, Maachi M, QuignardBoulange A, Capeau J, et al. Long-term treatment with interleukin$1 \mathrm{~b}$ induces insulin resistance in murine and human adipocytes. Diabetologia 2006;49:2162-73.

33. Manousopoulou A, Koutmani Y, Karaliota S, Woelk CH, Manolakos ES, Karalis K, et al. Hypothalamus proteomics from mouse models with obesity and anorexia reveals therapeutic targets of appetite regulation. Nutr Diabetes 2016;6:e204.

34. Lafontan M. Adipose tissue and adipocyte dysregulation. Diabetes Metab 2014;40:16-28.

35. McDougall GJ, Kulkarni NN, Stewart D. Current developments on the inhibitory effects of berry polyphenols on digestive enzymes. Biofactors 2008;34:73-80.

36. Seeram NP. Berry fruits: Compositional elements, biochemical activities, and the impact of their intake on human health, performance, and disease. J Agric Food Chem 2008;56:627-9.

37. Sugimoto M, Arai H, Tamura Y, Murayama T, Khaengkhan P, Nishio T, et al. Mulberry leaf ameliorates the expression profile of adipocytokines by inhibiting oxidative stress in white adipose tissue in $\mathrm{db} / \mathrm{db}$ mice. Atherosclerosis 2009;204:388-94.

38. Matsuzawa-Nagata N, Takamura T, Ando H, Nakamura S, Kurita S,
Misu $\mathrm{H}$, et al. Increased oxidative stress precedes the onset of high-fat diet-induced insulin resistance and obesity. Metabolism 2008;57:1071-7.

39. Abu-Gabal NS, Abd-Alla HI, Mohamed NZ, Aly HF, Shalaby NM. Phenolics composition, hypolipidemic, hypoglycemic and antioxidative effects of the leaves of Fortunella japonica (Thunb.) Swingle. Int J Pharm Pharm Sci 2015;7:55-63.

40. Kalsi A, Singh S, Taneja N, Kukal S, Mani S. Current treatments for Type 2 diabetes, their side effects and possible complementary treatments. Int J Pharm Pharm Sci 2014;7:13-8.

41. Su HM, Feng LN, Zheng XD, Chen W. Myricetin protects against dietinduced obesity and ameliorates oxidative stress in C57BL/6 mice. J Zhejiang Univ Sci B 2016;17:437-46.

42. Tag HM. Hepatoprotective effect of mulberry (Morus nigra) leaves extract against methotrexate induced hepatotoxicity in male albino rat. BMC Complement Altern Med 2015;15:252.

43. Gaidhu MP, Anthony NM, Patel P, Hawke TJ, Ceddia RB. Dysregulation of lipolysis and lipid metabolism in visceral and subcutaneous adipocytes by high-fat diet: Role of ATGL, HSL, and AMPK. Am J Physiol Cell Physiol 2010;298:C961-71.

44. Abd-Alla HI, Albalawy MA, Aly HF, Shalaby NM, Shaker KH. Flavone composition and antihypercholesterolemic and antihyperglycemic activities of Chrysanthemum coronarium L. Z Naturforsch C 2014;69:199-208. 